\title{
Testing Some Fungicides for the Combat of Potato Mildew in the Pedoclimatic Conditions in Seini Town
}

\author{
Lucia MIHALESCU ${ }^{1 *}$, Zorica VOŞGAN ${ }^{1}$, Oana MARE ROŞCA ${ }^{1}$, Monica MARIAN ${ }^{1}$, Stela JELEA ${ }^{1}$, Anca \\ DUMUȚA $^{1}$, Aurel MAXIM ${ }^{2}$, Mirela CORDEA ${ }^{2}$, Melania OLTEAN ${ }^{3}$ \\ ${ }^{1}$ Department of Biology, Technical University of Cluj Napoca, North University Center of Baia Mare, \\ no.76, Victoriei Street, Romania \\ ${ }^{2}$ University of Agricultural Sciences and Veterinary Medicine, Cluj-Napoca, Romania \\ ${ }^{3}$ Phytosanitary National Authority - Maramures Phytosanitary Office, Baia Mare, no.70, Vasile \\ Alecsandri street, Romania \\ *Corresponding author: luciamihalescu@yahoo.com
}

Bulletin USAMV series Agriculture 72(2)/2015

Print ISSN 1843-5246; Electronic ISSN 1843-5386

DOI 10.15835/buasvmcn-agr: 11389

\begin{abstract}
The aim of this survey was to set the biologic effectiveness of some homologated fungicides, in order to introduce them in the new programs of combating mildew in potato crops. The experimental surveys were carried out at the farm of SC Marmalus SRL of Seini, the Maramures County, during 2013 and 2014. The warning area method was used. The attack was calculated by determining the attack frequency, intensity and degree. In 2013, 8 varieties were tested against the mildew attack, as the Procura variant proved to be the most resistant, and Ostara the most sensible. In 2014, 14 fungicides were tested starting with the outbreaks of the alarm plot; then the appearance of mildew in natural conditions was taken into account. For testing, the sensible Ostara variety and the resistant Procura variety were used. The climatic conditions were favorable to the development of fungi, with high temperatures and atmospheric humidity. The best results were obtained for the Ridomil Gold Plus 42.5WG, for both varieties, with the effectiveness of $86.6 \%$ for the resistant variety, respectively, $85 \%$ for the sensitive variety. The worst results were obtained by the Dithane M45 product, with an effectiveness of $70.4 \%$ for Ostara, as for the Procura variant the Polyram DF product was used with an effectiveness of $73.7 \%$. In the combating of Phythophtora infestans fungi, it is recommended to use with good results the product Ridomil Gold Plus 42.5WG, followed by the products Ridomil Gold X9Z86WG, Infinito 68.7 SC and Consento 450 SC.
\end{abstract}

Keywords: attack, fungicide, mildew, variety, warning

\section{INTRODUCTION}

In Romania, potatoes are appreciated food due to their nutritive qualities (Berindei, 1985). For all of its benefits we need a healthy cultivation of potatoes that gives a high degree of yield (Stefan, 2005).

However, mildew is one of the oldest known diseases and it continues to be the most damaging one due to the aggressiveness of Phythophtora infestans fungi, in climatic conditions favorable to their development (Ion, 2010).
The knowledge of the strength or sensitivity degree of the varieties is essential in the differentiate application of the treatments for reducing their number, with the condition of ensuring an optimum effectiveness ( $\operatorname{Sin}, 2005)$.

The chemical products prove their effectiveness only in the condition of their rational use, and utilizing them indiscriminately leads to low, qualitatively depreciated crops (Botoman et al., 2005). 


\section{MATERIALS AND METHODS}

The experimental surveys were carried out at the farm of SC Marmalus SRL of Seini, the Maramures County, during 2013 and 2014. In 2013, 8 varieties (Ostara, Gloria, Sucevita, Desiree, Sante, Super, Procura, Semenic) were tested against the mildew attack, as the Procura variant proved to be the most resistant, and Ostara the most sensitive. The experimental plot has an area of 0.5 ha. In 2014, 14 fungicides were tested starting with the outbreaks of the alarm plot; then the appearance of mildew in natural conditions was taken into account. For testing, the sensible Ostara variety and the resistant Procura variety were used. The following fungicides were tested: $\mathrm{V}_{1}$ - Ridomil Gold MZ68WG, $\mathrm{V}_{2}$ - Ridomil Gold Plus 42.5WP, $V_{3}$ - Flowbrix, $V_{4}$ - Curzale Manox, $\mathrm{V}_{5}$ - Triumf40WG, $\mathrm{V}_{6}$ - Acrobat MZ90/600, $\mathrm{V}_{7}$ Antracol, $V_{8}-$ Polyram DF, $V_{9}$ - Equation PRO, $V_{10}$ - Ortiva 230EC, $\mathrm{V}_{11}$ - Dilthane M45, $\mathrm{V}_{12}$ - Bravo 500SC, $\mathrm{V}_{13}$ - Consento 450SC, $\mathrm{V}_{14}$ - Infinito 68.7SC.

The warning method used an experimental area. This zone was isolated from the potato fields, and it was representative for the climate of the fields that the warning was to be emitted. The potatoes used for cultivation were the most sensitive and the less sensitive to mildew attack. Subsequent to the outbreak of the first secondary infection, the warning area was chemically destroyed, not to be an infection source for the neighboring fields. By this warning method, mildew was treated in time, and the epidemic outbreak in the fields was avoided. By the assessment methods, the frequency, intensity and degree of the mildew attack were determined. The agrometeorological data were recorded by the Agroexpert System. The assessment of the method effectiveness was achieved using the control sample technique.

\section{RESULTS AND DISCUSSION}

In 2013 an experiment with no chemical treatments was set up to find the strength of the varieties, intending for choosing the sort of varieties that were to be tested to fungicides, as the behavior of 8 varieties with different characteristics grown under conditions of artificial infestation was monitored. Every variant was planted on a row, and then a row of artificially infected potatoes was planted, the operation being repeated until planting all the studied varieties. In these plots, no chemical treatments against mildew were carried out, in order to observe the behavior of these varieties. The climatic conditions were favorable to the development of mildew, with high temperatures and atmospheric humidity.

The obtained results are presented in Tab.1.

Among the 8 studied varieties, the Procura variant proved to be the most resistant to the mildew attack, the attack degree on the foliage area being extremely week; and the most sensitive the Ostara variant. During 2014, a range of 14 fungicides for potato mildew combat were tested. The products were used by treatments carried out during the vegetation period, starting with the mildew outbreaks in the warning area, and then the mildew outbreak under natural conditions in the monitored fields was considered. These treatments were used for the two variants, as Ostara was the most sensitive and Procura the most resistant.

Tab.1. The behavior of some potato varieties to the mildew attack, in the experimental area of SC Marmalus SRL Seini, in the conditions of 2013

\begin{tabular}{|c|c|c|c|c|c|c|c|}
\hline \multirow{3}{*}{ Variety } & \multirow{3}{*}{ Phytopathogene Agent } & \multirow{3}{*}{$\begin{array}{c}\text { MU } \\
\text { GA\% }\end{array}$} & \multicolumn{5}{|c|}{ Assessment of the attack on the leaves } \\
\hline & & & weak & medium & strong & very strong & extremely strong \\
\hline & & & $<10$ & $10-25$ & $25-50$ & $50-75$ & $>75$ \\
\hline Ostara & Phytophtora infestans & GA $\%$ & - & 0.1 & 0.3 & 0.3 & 0.1 \\
\hline Gloria & Phytophtora infestans & GA\% & - & 0.2 & 0.1 & 0.1 & 0.1 \\
\hline Sucevita & Phytophtora infestans & $\mathrm{GA} \%$ & 0.1 & 0.0 & 0.2 & 0.1 & 0.1 \\
\hline Desiree & Phytophtora infestans & $\mathrm{GA} \%$ & 0.3 & 0.2 & - & - & - \\
\hline Sante & Phytophtora infestans & $\mathrm{GA} \%$ & 0.3 & 0.2 & - & - & - \\
\hline Super & Phytophtora infestans & GA\% & - & 0.1 & 0.2 & 0.1 & 0.1 \\
\hline Procura & Phytophtora infestans & $\mathrm{GA} \%$ & 0.5 & 0.0 & 0.0 & 0.0 & 0.0 \\
\hline Semenic & Phytophtora infestans & GA $\%$ & 0.4 & 0.1 & - & - & - \\
\hline
\end{tabular}


The effectiveness of the tested fungicides for the Procura variant is observed in Fig.1, and for the Ostara variant in Fig. 2.

From the experimental data, in Fig. 1 we observe that for the Procura variant, which is resistant to the foliage mildew attack, al the 14 variants have close values, being situated well bellow the values of the untreated control sample. We observe a decrease of the foliage attack intensity from $62.5 \%$, to $9.7 \%$ in the case of the untreated control sample, with an effectiveness of
$86.6 \%$ in the $V_{2}$ case. In the cases of the variants $\mathrm{V}_{1}, \mathrm{~V}_{6}, \mathrm{~V}_{9}$ the effectiveness of the products was situated between 85-86.3\%, these being very good results. In the variants $\mathrm{V}_{3}, \mathrm{~V}_{4}, \mathrm{~V}_{5}, \mathrm{~V}_{7}, \mathrm{~V}_{13}, \mathrm{~V}_{14}$ the effectiveness was comprised between 80.5$85.2 \%$ and in the variants $\mathrm{V}_{8}, \mathrm{~V}_{10}, \mathrm{~V}_{11}$ and $\mathrm{V}_{12}$ the effectiveness was lower, respectively bellow $80 \%$, the $\mathrm{V}_{8}$ variant having the worst result with an effectiveness of only $73.7 \%$. Fig. 2 shows the results of the experiment for the Ostara variant, which is sensitive to the foliage mildew attack, all

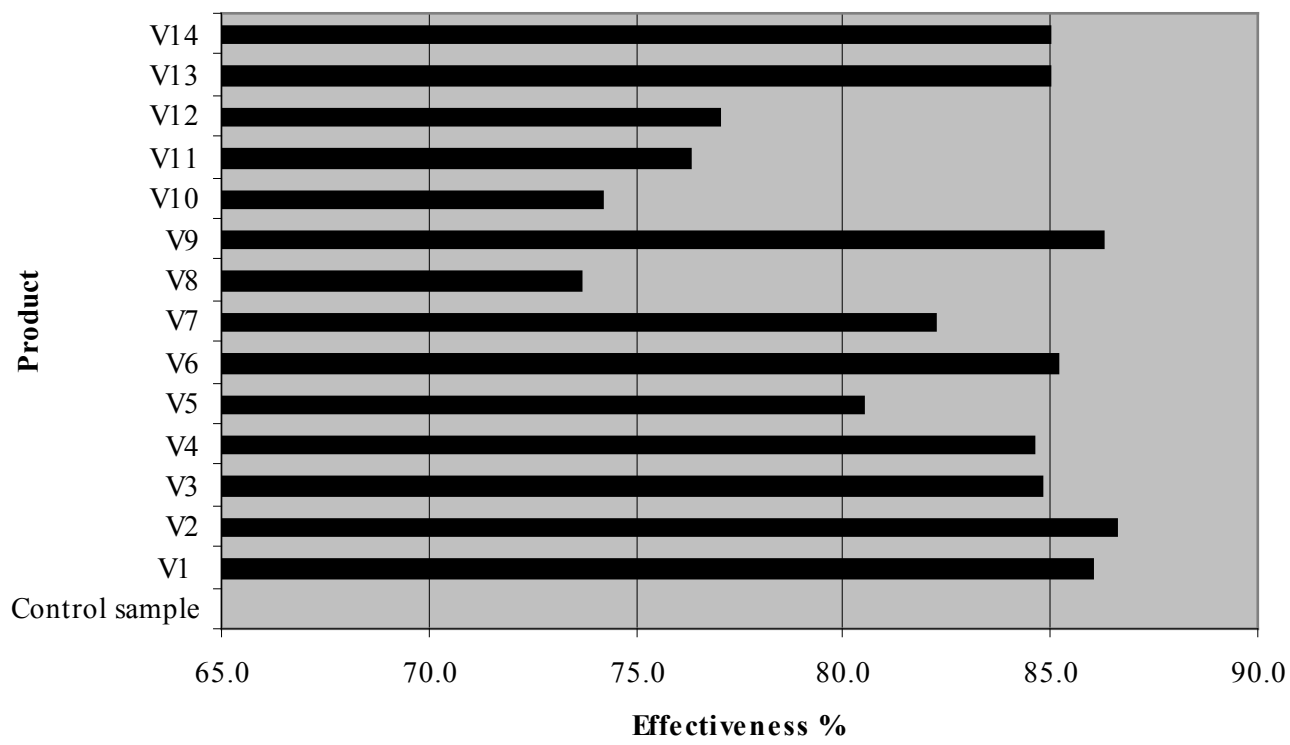

Fig.1. Effectiveness of the tested fungicides for the Procura variant

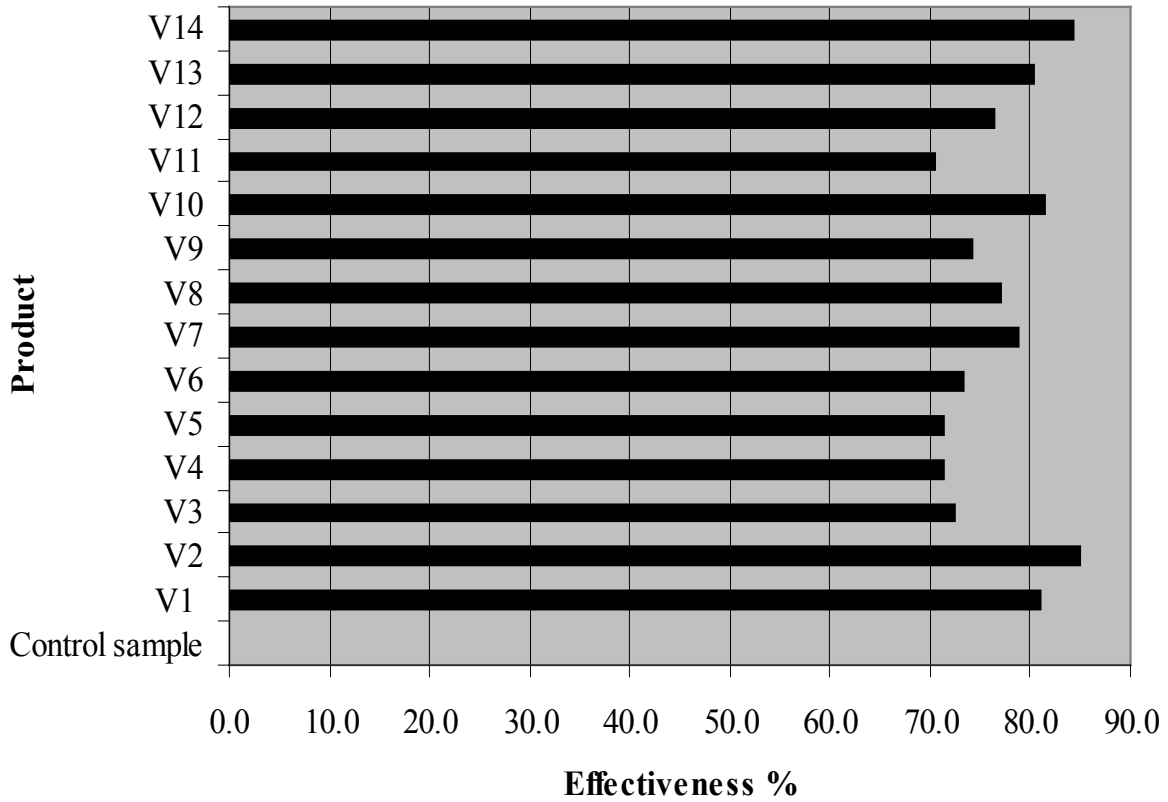

Fig. 2. Effectiveness of the tested fungicides for the Ostara variant 


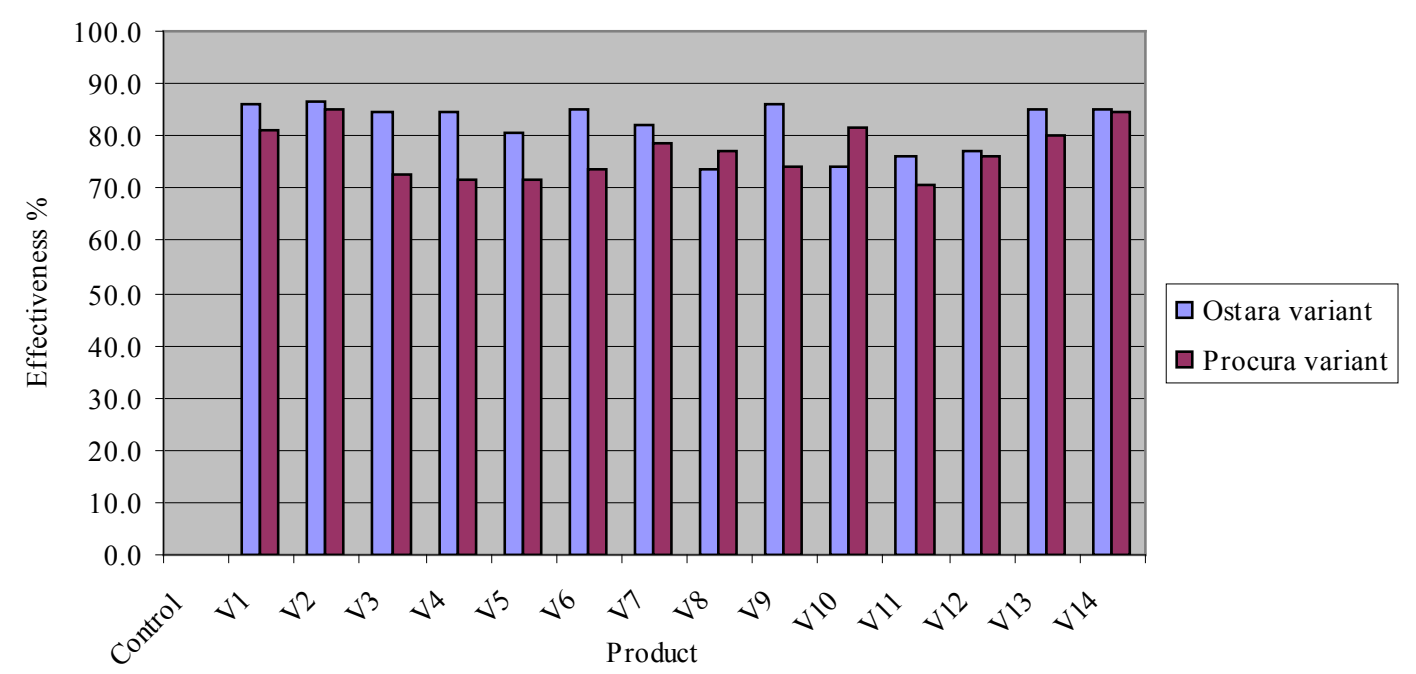

Fig. 3. Testing the effectiveness of some fungicides for the mildew combat for the chosen variants

the 14 variants having close values, being situated well bellow the untreated control sample.

A decrease of the foliage mildew attack was observed from $70.7 \%$ in the case of the untreated control sample to 10.5 , with an effectiveness of $85 \%$ in the $V_{2}$ case. It was found that among the 14 variants, four of them $\left(\mathrm{V}_{1}, \mathrm{~V}_{10}, \mathrm{~V}_{13}, \mathrm{~V}_{14}\right)$ presented values comprised between 80.3-84\%, these being considered very good results in the mildew combat. The variants $\mathrm{V}_{3}, \mathrm{~V}_{4}, \mathrm{~V}_{5}, \mathrm{~V}_{6}, \mathrm{~V}_{7}, \mathrm{~V}_{8}, \mathrm{~V}_{9}, \mathrm{~V}_{12}$ achieved an effectiveness of 71.4-78.8\%, and in the case of the variant $\mathrm{V}_{11}$ was achieved the worst effectiveness of $70.4 \%$.

The analyses of the results of the two variants showed that the product of $\mathrm{V}_{2}$ (Ridomil Gold Plus 42.5WP) proved the best effectiveness, respectively, for the Procura variant $86.6 \%$, and for Ostara $85.0 \%$, as it is a double action fungicide, i.e. systemic and by contact, containing active substances like mefenoxam and copper. The effectiveness of all the 14 tested products for the Ostara variant was lower than that for the Procura variant, due to its higher sensitivity to mildew. The worst tested fungicide was Polyram DF for the Procura variant, achieving an effectiveness of only 73.7\%, and Dilthane M45 for the Ostara variant the worst effectiveness of $70.4 \%$, both of them being contact products, the first containing metiran, and the second mancozabul, as active substances.

Fig. 3 shows the comparison of the biologic effectiveness of the 14 tested fungicides for the two chosen variants:
The biologic effectiveness of fungicides in mildew combat, in order to introduce them in the new mildew combat programs of the potato cultivation, was monitored during this research.

\section{CONCLUSION}

As the development of Phytophtora infestans mildew is influenced by the climatic conditions, these were monitored by the Agroexpert system, during the two research years. 2013 was not favorable for the development of mildew, as it was a dry year, and mildew was signaled only at the beginning of the vegetation period with a weak attack degree. The meteorological conditions that were recorded in 2014 at Seini, characterized by high temperatures, high atmospheric humidity, favored the development of Phytophtora infestans mildew.

Following the effectiveness testing of 14 homologated fungicides, for the sensitive Ostara variant and the resistant variant Procura, the best results were obtained for the Ridomil Gold Plus $42.5 \mathrm{WG}$, with the effectiveness of $86.6 \%$ for the resistant variety, respectively, $85 \%$ for the sensitive one. The product has double actions, i.e. systemic and by contact, as it is containing active substances like mefenoxam and copper.

The worst results were obtained for Dilthane M45 with the effectiveness of $70.4 \%$ for the Ostara variant, and for the Procura variant, the Polyram DF product with an effectiveness of only $73.7 \%$. Both products are by contact action, concluding 
that the effectiveness is higher for the systemic products.

According to this survey, in the combating of Phythophtora infestans fungi, it is recommended to use with good results the product Ridomil Gold Plus 42.5WG, followed by the products Ridomil Gold MZ86WG, Infinito 68.7 SC and Consento 450 SC.

\section{REFERENCES}

1. Berindei M (1985). Ghidul Fermierului - Cultura cartofului. Ed. Ceres, Bucuresti.

2. Botoman G, Ianosi SI (2005). Combaterea integrata a bolilor si daunatorilor din cultura cartofului. Editura Valahia Bucuresti.

3. Ion V (2010). Fitotehnie. Ed. Bucuresti.

4. Sin G (2005). Managementul tehnologic al culturilor de camp. Editura Ceres Bucuresti.

5. Stefan V (2005). Tehnici de cultivare. Editura Nemira Bucuresti 